Article

\title{
Influence of Thermal Conditions on Particle Properties in Fluidized Bed Layering Granulation
}

\author{
Christoph Neugebauer ${ }^{1, *}$, Andreas Bück ${ }^{2}$ (i) , Stefan Palis ${ }^{1}$, Lisa Mielke ${ }^{3}$, Evangelos Tsotsas ${ }^{3}$ \\ and Achim Kienle ${ }^{1,4}$ \\ 1 Chair for Automation/Modelling, Otto von Guericke University, D-39106 Magdeburg, Germany; \\ stefan.palis@ovgu.de (S.P.); kienle@mpi-magdeburg.mpg.de (A.K.) \\ 2 Institute of Particle Technology, Friedrich-Alexander University Erlangen-Nürnberg, D-91054 Erlangen, \\ Germany; andreas.bueck@fau.de \\ 3 Chair for Thermal Process Engineering, Otto von Guericke University, D-39106 Magdeburg, Germany; \\ lisa.mielke@ovgu.de (L.M.); evangelos.tsotsas@ovgu.de (E.T.) \\ 4 Process Synthesis and Process Dynamics (PSD), Max Planck Institute for Dynamics of Complex Technical \\ Systems, D-39106 Magdeburg, Germany \\ * Correspondence: neugebauer@mpi-magdeburg.mpg.de; Tel.: +49-391-67-51510
}

Received: 25 September 2018; Accepted: 16 November 2018; Published: 22 November 2018

\begin{abstract}
Fluidized bed layering granulation is frequently used to formulate particles of high quality. From previous studies, it is well known that the dynamic behavior of the process, as well as the product properties depend on operating parameters. The process is characterized by heat and mass transfer between fluidized particles and the surrounding fluidization medium. To investigate the mutual influence between particle phase and fluidization medium, a dynamic model is introduced. The model comprises two parts: a population balance model to describe the evolution of the particle sizes and a system of ordinary differential equations to account for thermal conditions. For the first time, the dynamic model considers the bidirectional coupling of particles and fluidization medium in fluidized bed layering granulation. By means of simulations, it is shown that the derived model is capable of reproducing the experimental findings.
\end{abstract}

Keywords: fluidized bed; layering granulation; population balance; drying; dynamics

\section{Introduction}

Fluidized bed layering granulation (FBLG) is a widely-applied particle formulation process. For instance, pharmaceutical, food, and fertilizer industries utilize FBLG to produce granules of high quality (Mörl et al. [1]). Therein, a solid-containing liquid, for instance a suspension or solution, is sprayed onto fluidized particles. Since the fluidization medium is heated, the liquid content of the spray evaporates, while the solid remains on particles surface, leading to a layer-wise growth, as illustrated in Figure 1 (Tsotsas [2]). As a result, the solid product is more durable and easier to handle than its liquid equivalent. Since the produced granules are often an intermediate product in a process chain, subsequent process steps require specific particle properties. For example, more than a minimum particle strength prevents breakage and dust formation during transport (Antonyuk et al. [3]), whereas solubility is a key feature if the granules have to be dissolved at a later stage.

To achieve high throughput, FBLG is operated in continuous mode. As particles are removed from the process continuously, nuclei have to be supplied permanently. Depending on the configuration of the FBLG, seed nuclei have to be provided by internal sub-processes such as 
overspray (Grünewald et al. [4]) or, as presented in Figure 2, by comminution of oversized particles (Cotabarren et al. [5]).

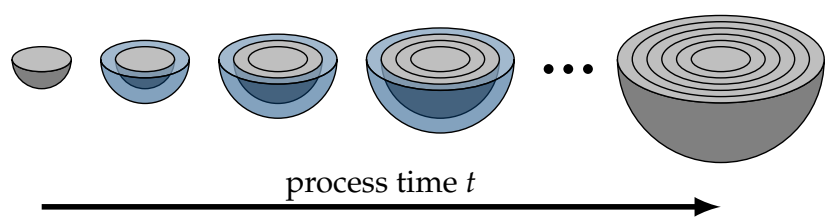

Figure 1. Scheme of layer-wise particle growth.

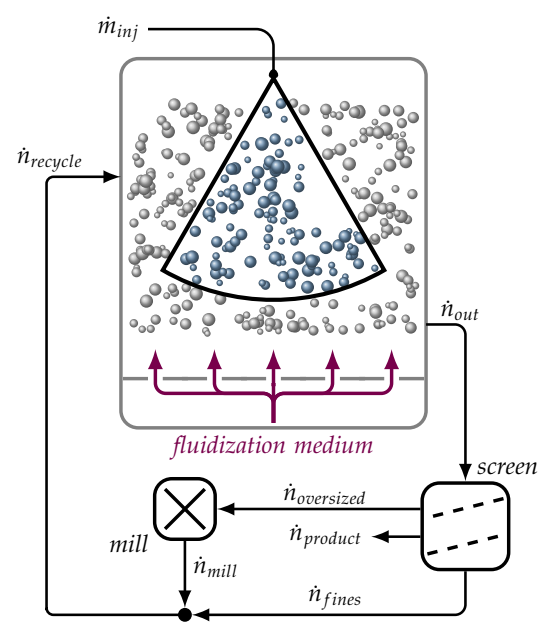

Figure 2. Continuous fluidized bed layering granulation with external screen-mill-cycle.

As Schmidt et al. [6-8] proved by experiments, operating parameters influence the dynamic behavior of the continuous FBLG significantly: while one parameter set $\Pi_{1}$ leads to a stable steady state, characterized by a constant particle size distribution over time, a second parameter set $\Pi_{2}$ may induce self-sustained oscillations. Thus, the process is classified as stable for $\Pi_{1}$ and unstable for $\Pi_{2}$.

Besides the dynamic behavior, process conditions affect the solidification process and thereby the product properties. The influence of selected process conditions on product porosity as a key property was investigated by Rieck et al. [9] and Hoffmann et al. [10] for the formation of sodium benzoate granules. The underlying solidification process was studied in great detail by Sondej et al. [11]. Therein, the influence of different operation parameters on the structure of the deposits from drying a sessile sodium benzoate droplet was studied. It was shown that the initial concentration of the solid in the droplet, as well as the thermal conditions of the surrounding fluidization medium influence the porosity and footprint of the remaining salt deposit. To account for thermal conditions within the FBLG, Rieck et al. [9] introduced the drying potential $\eta$. For granulation of sodium benzoate, a linear relation between the drying potential $\eta$ and the porosity of the particle shell $\epsilon_{\text {shell }}$ was found experimentally by Rieck et al. [9] and Hoffmann et al. [10] for FBLG with top spray configuration. Diez et al. [12] showed that a linear correlation between $\epsilon_{\text {shell }}$ and $\eta$ also holds for a bottom spray configuration. Since the particle strength, and thereby breakage behavior of particles, depends on porosity, it is an important property. Further relevant properties are the apparent particle density $\rho_{p}$ and average moisture content $X$ of product particles.

As a supplement to experiments, simulations are a promising way to investigate FBLG and improve the process understanding. As Ramkrishna [13] showed, population balance models are a suitable framework to derive dynamic models of particulate processes. In previous studies, numerous authors established a variety of population balance models (PBMs) for different process configurations and purposes. For instance, Vreman et al. [14] and Heinrich et al. [15] studied the dynamic behavior of FBLG. While Vreman et al. [14] investigated the dynamics of FBLG with 
internal nucleation by thermal overspray, the start-up behavior of an FBLG equipped with an external screen-mill-cycle was in the focus of Heinrich et al. [15]. Based on the PBM presented by Heinrich et al. [15], Radichkov et al. [16] investigated the influence of operation parameters on the qualitative behavior of the process by means of a rigorous stability analysis. So far, the dynamic models assumed an equal wetting of particle surface, leading to a uniform particle growth. From the nature of the process, as shown in Figure 2, it becomes clear that not all particles are sprinkled at a time. Therefore, Hampel et al. [17], Dreyschultze et al. [18], and Neugebauer et al. [19] introduced a dynamic model with two interconnected functional zones: wet and drying zone. In the first, particles are sprinkled with the injected liquid, while in the second, drying of the particles takes place. Based on the derived models, Dreyschultze et al. [18], Bück et al. [20], and Neugebauer et al. [19] investigated the influence of zone formation and process configurations on process behavior by means of a rigorous stability analysis. However, thermal conditions were not taken explicitly into account. Further, it turned out that the effect of zone formation on overall dynamics is often small and is therefore neglected throughout this contribution.

Models that consider the thermal condition were presented by Drechsler et al. [21] and Dosta et al. [22]. There, the impact of the particulate phase on the thermal states was studied. On the contrary, the models did not consider the influence of thermal conditions on particle properties. Thus, the models presented so far are not capable of predicting any product property besides particle size $L$.

In the present contribution, the interplay of thermal conditions and product properties, as well as the dynamic behavior of the FBLG depicted in Figure 2 is studied. Therefore, the population balance model presented by Radichkov et al. [16] is extended by a system of ordinary differential equations to account for thermal conditions. The correlation of $\eta$ and $\epsilon_{\text {shell }}$, as presented by Rieck et al. [9] and Hoffmann et al. [10], is utilized to link thermal conditions and particle growth. The developed dynamic model is presented in Section 2. In Section 3, the influence of operating parameters on product properties, as well as the interplay of particulate phase and thermal conditions are investigated by means of process simulations for granulation of sodium benzoate. Finally, conclusions and an outlook on future work are given in Section 4.

\section{Mathematical Model}

The coupling of particles and the surrounding fluidization medium is characteristic for FBLG. Both particles and fluidization medium are characterized by various properties. A particle for instance can be described by the corresponding individual size, temperature, and moisture content, while the state of the fluidization medium is determined by its temperature and moisture. From the operator's point of view, the size of particles is often a key property in particulate processes such as FBLG. To gain detailed information about the size of all particles within the bed, the particle size distribution $n(t, L)$ is introduced. It represents the number of particles with size $L$ at specific time $t$. To describe the dynamic behavior of $n(t, L)$, a population balance model (PBM) is introduced. Further important process variables are the temperature, moisture content, and dry mass of particles and fluidization medium, respectively. It is assumed that both particles and fluidization medium are well mixed. Therefore, the temperature of particles $\theta_{p}(t)$ and fluid $\theta_{f}(t)$, the moisture content of particles $X(t)$ and fluid $Y(t)$, and the dry mass of particles $m_{p, d r y}(t)$ and fluid $m_{f, d r y}(t)$ can be modeled as lumped states. The dynamic behavior of those states is described by ordinary differential equations. In the remainder of this section, the dynamic model of the FBLG is introduced. The proposed model describes continuously-operated FBLG with the external screen-mill-cycle only. However, to account for further process configurations, e.g., a batch-wise operation, only slight adaptations of the dynamic model are required. As depicted in Figure 3, the model consists of two subsystems. The first subsystem is the PBM describing the dynamics of $n(t, L)$ over time $t$ and particle size $L$. The second subsystem, a system of ordinary differential equations (ODEs), describes the dynamics of the thermal conditions within the FBLG. It is derived by utilizing mass and energy balances. As will be shown, the two sub-systems are interconnected. 


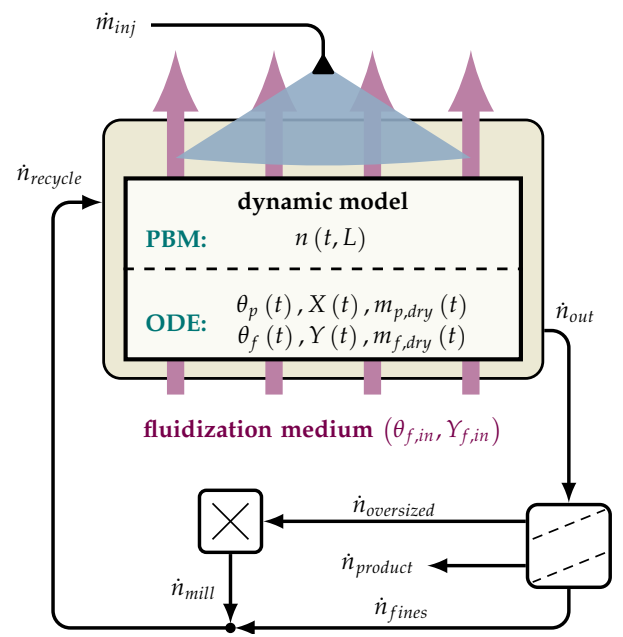

Figure 3. Flow sheet of fluidized bed layering granulation (FBLG). (PBM: population balance model; ODE: ordinary differential equation).

\subsection{Population Balance Model}

The presented PBM is based on the dynamic model of FBLG presented by Radichkov et al. [16]. To focus on characteristic process behavior, only particle growth, particle withdrawal, screening, and milling are considered. Breakage and aggregation can be neglected due to a proper choice of operation conditions in practice (Ennis et al. [23]). Therefore, the PBM reads:

$$
\frac{\partial n(t, L)}{\partial t}=-G \frac{\partial n(t, L)}{\partial L}+\dot{n}_{\text {recycle }}(t, L)-\dot{n}_{\text {out }}(t, L) .
$$

To determine the particle growth, the model presented by Mörl et al. [1] is utilized. Therein, a uniform particle growth is assumed depending on the total surface of the particle bed $A_{p}(t)=\pi \int_{0}^{\infty}\left(L^{2} n(t, L)\right) d L$. To account for the porosity of the particle shell $\epsilon_{\text {shell }}$, the growth model is extended:

$$
G=\frac{2 x_{i n j} \dot{m}_{i n j}}{\left(1-\epsilon_{\text {shell }}\right) \rho_{i n j, s} A_{p}}
$$

with the total spray rate $\dot{m}_{i n j}$, the solid fraction of the spray $x_{i n j}$, and the density of the solid fraction of the spray $\rho_{i n j, s}$. The shell porosity $\epsilon_{\text {shell }}$ correlates, as Rieck et al. [9] and Hoffmann et al. [10] showed for the layering granulation of sodium benzoate, linearly to the drying potential $\eta$ :

$$
\epsilon_{\text {shell }}=-\Delta \epsilon_{\text {shell }} \eta+\epsilon_{\text {shell }, 0} .
$$

The drying potential $\eta$, a measure of the efficiency of the drying process, is defined as the ratio between the actual drying rate and the drying rate at saturation:

$$
\eta=\left(Y_{\text {sat }}-Y\right) /\left(Y_{\text {sat }}-Y_{f, \text { in }}\right) .
$$

It depends on the moisture content of the fluidization medium inside the granulation chamber $Y$, the saturation moisture $Y_{\text {sat }}$, and the moisture of the fluidization medium at inlet $Y_{f, i n}$. The corresponding parameters $\Delta \epsilon_{\text {shell }}$ and $\epsilon_{\text {shell }, 0}$ are presented in the experimental study Rieck et al. [9]. The apparent average porosity of particles is defined as: 


$$
\epsilon_{p}=\left(1-\frac{m_{p, d r y} / \rho_{i n j, s}}{(\pi / 6) \int_{0}^{\infty} L^{3} n(t, L) d L}\right) .
$$

Since the investigated FBLG is operated continuously, product particles have to be withdrawn from the process, while nuclei have to be supplied. To remove particles from the FBLG, the non-classifying particle withdrawal $\dot{n}_{\text {out }}(t, L)=K n(t, L)$ is applied. The outlet gain is determined such that the bed mass $m_{p}$ is constant over time:

$$
K=\frac{-G\left(1-\epsilon_{\text {shell }}\right) \int_{0}^{\infty}\left(L^{3 \partial \eta(t, L) / \partial L}\right) d L}{\left(1-\epsilon_{p}\right) \int_{0}^{\infty}\left(L^{3} n(t, L)\right) d L} .
$$

The withdrawn particles are classified by screening, according to:

$$
\begin{aligned}
\dot{n}_{\text {oversized }}(t, L) & =T_{\text {screen }, I} \dot{n}_{\text {out }}(t, L) \\
\dot{n}_{\text {product }}(t, L) & =\left(1-T_{\text {screen }, I}\right) T_{\text {screen }, I I} \dot{n}_{\text {out }}(t, L) \\
\dot{n}_{\text {fines }}(t, L) & =\left(1-T_{\text {screen }, I}\right)\left(1-T_{\text {screen }, I I}\right) \dot{n}_{\text {out }}(t, L)
\end{aligned}
$$

into oversized $\dot{n}_{\text {oversized }}$, product $\dot{n}_{\text {product }}$, and fines fraction $\dot{n}_{\text {fines }}$. The separation function $T_{\text {screen, }, i}$ is described by:

$$
T_{\text {screen }, i}(L)=\frac{\int_{0}^{L} \exp \left(-\left(L-\mu_{\text {screen }, i}\right)^{2} /\left(2 \sigma_{\text {screen }, i}^{2}\right)\right) d L}{\int_{0}^{\infty} \exp \left(-\left(L-\mu_{\text {screen }, i}\right)^{2} /\left(2 \sigma_{\text {scren }, i}^{2}\right)\right) d L} .
$$

While the product fraction is removed from the process, the oversized fraction is milled and, together with fines fraction, re-fed to the granulation chamber, as illustrated in Figure 3:

$$
\dot{n}_{\text {recycle }}(t, L)=\dot{n}_{\text {mill }}(t, L)+\dot{n}_{\text {fines }}(t, L) \text {. }
$$

Thereby, the milled particles $\dot{n}_{\text {mill }}$ serve as nuclei for the granulation process. In general, milling of granules is a complex process. For instance, the configuration of the mill itself, as well as particle properties, e.g., porosity, shape, and size, have a significant influence on the breakage behavior of particles (Antonyuk et al. [3]). Since this contribution focuses on the influence of thermal conditions on product properties in FBLG, an idealized model of the grinding process is utilized. It is assumed that the mill imprints the normalized particle size distribution $q_{\text {mill }}(L)$ on the oversized particles $\dot{n}_{\text {oversized }}$ :

$$
\dot{n}_{\text {mill }}(t, L)=\frac{q_{\text {mill }}(L) \int_{0}^{\infty}\left(L^{3} \dot{n}_{\text {oversized }}(t, L)\right) d L}{\int_{0}^{\infty}\left(L^{3} q_{\text {mill }}(L)\right) d L},
$$

where $q_{\text {mill }}(L)$ is considered as normally distributed with mean diameter $\mu_{\text {mill }}$ and variance $\sigma_{\text {mill }}^{2}$.

\subsection{Heat and Mass Transfer}

The dynamic behavior of thermal conditions within FBLG is described by six states: temperature of particles $\theta_{p}(t)$ and fluid $\theta_{f}(t)$, moisture content of particles $X(t)$ and fluid $Y(t)$, the mass of the dry hold-up of particles $m_{p, d r y}(t)$, and fluidization medium $m_{f, d r y}(t)$. To derive the corresponding state equations, mass and enthalpy balances are used, assuming an ideally-mixed system. 
The moisture contents of particle and fluid phase are defined as ratios of solvent to dry mass such that $X(t)=m_{p, \text { solvent }} / m_{p, d r y}$ and $Y(t)=m_{f, \text { solvent }} / m_{f, d r y}$. To describe the temporal behavior, the time derivatives of $X(t)$ and $Y(t)$ :

$$
\dot{X}(t)=\left(\dot{m}_{p, \text { solvent }}-X \dot{m}_{p, d r y}\right) / m_{p, d r y} \quad \text { and } \quad \dot{Y}(t)=\left(\dot{m}_{f, \text { solvent }}-Y \dot{m}_{f, d r y}\right) / m_{f, d r y}
$$

are derived. The required time derivatives of the solvent and the dry mass of the particle and fluid phase result from balancing the mass flows:

$$
\begin{aligned}
\dot{m}_{p, d r y}(t) & =x_{i n j} \dot{m}_{i n j}+\dot{m}_{p, r e c y c l e, d r y}-\dot{m}_{p, o u t, d r y} \\
\dot{m}_{p, \text { solvent }}(t) & =\left(1-x_{i n j}\right) \dot{m}_{i n j}+X_{\text {recycle }} \dot{m}_{p, \text { recycle,dry }}-X \dot{m}_{p, o u t, d r y}-\dot{m}_{\text {evap }} \\
\dot{m}_{f, d r y}(t) & =\dot{m}_{f, d r y, \text { in }}-\dot{m}_{f, d r y, \text { out }} \\
\dot{m}_{f, \text { solvent }}(t) & =Y_{f, \text { in }} \dot{m}_{f, d r y, \text { in }}-Y \dot{m}_{f, d r y, \text { out }}+\dot{m}_{\text {evap }}
\end{aligned}
$$

While $x_{i n j}, \dot{m}_{i n j}$, mass flow $\dot{m}_{f, d r y, i n}$, and moisture of fluidization medium at inlet $Y_{f, i n}$, as well as the mass flow of fluidization medium at outlet $\dot{m}_{f, d r y, o u t}$ are operation parameters, the mass flows of the recycle $\dot{m}_{p, \text { recycle,dry }}$ and of the outlet $\dot{m}_{p, o u t, d r y}$ depend on the PBM presented in Section 2.1. They are determined by $\dot{m}_{p, i, d r y}(t)=\left(1-\epsilon_{p, i}\right) \rho_{i n j, s}(\pi / 6) \int_{0}^{\infty}\left(L^{3} \dot{n}_{i}(t, L)\right) d L$ for $i=\{$ out, recycle $\}$. The mass flow rate $\dot{m}_{\text {evap }}$ denotes the mass transfer of evaporated solvent from particle phase to fluidization medium. Since the evaporation decreases the moisture of particles $X$, drying takes place.

In general, drying describes the exchange of mass and heat between a solid and a fluid due to evaporation of a liquid. According to van Meel [24], the drying process consists of three periods. As illustrated in Figure 4, the first drying period is characterized by $X \geq X_{\text {crit }}$, where $X_{\text {crit }}$ denotes the critical moisture of particles. In this period, the evaporation of the solvent is limited by the state of the fluidization medium only. In the second period, $X_{\text {crit }} \leq X \leq X_{\text {eq }}$, the evaporation rate decreases due to particle-side resistances. In the third drying period, the particle moisture $X$ is, however, below the thermodynamic adsorption equilibrium moisture $X_{e q}$ such that $X<X_{e q}$ is yielded. In this period, no further drying takes place.

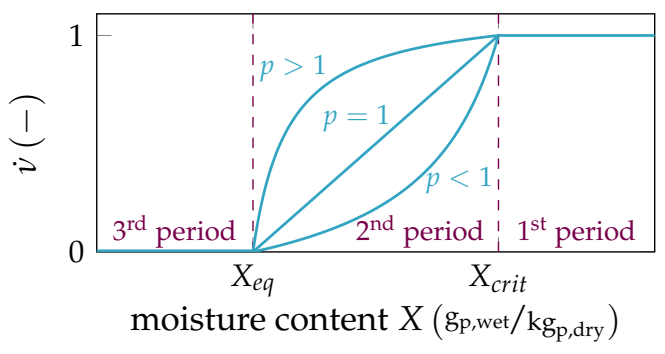

Figure 4. Normalized drying velocity $\dot{v}$ over moisture content of particles $X$ as introduced by van Meel [24] dependent on different $p$.

To address the decrease of the evaporation rate $\dot{m}_{\text {evap }}$ over the drying periods, van Meel [24] introduced the normalized drying velocity $\dot{v}$, defined as the ratio of the actual evaporation rate to the maximal evaporation rate that occurs in first drying period. Therefore, $\dot{v}$ is unity in the first period, while it becomes zero in third period. In the second drying period, $\dot{v}$ depends on the particle moisture $X$ such as specific material properties. To address the influence of material properties on drying characteristics, the parameter $p$ is introduced. Thus, the normalized drying velocity can be written as:

$$
\dot{v}(\delta)=\left\{\begin{array}{lr}
1 & X \geq X_{\text {crit }} \\
\frac{p \delta(X)}{1+(p-1) \delta(X)} & X_{\text {crit }}>X \geq X_{\text {eq }} \\
0 & X_{\text {eq }}>X
\end{array}\right.
$$


where $\delta$ describes the normalized moisture content, which is determined by $\delta(X)=\left(X-X_{e q}\right) /\left(X_{c r i t}-X_{e q}\right)$. The influence of the drying period and parameter $p$ on $\dot{v}$ is depicted in Figure 4. The difference between saturation moisture $Y_{\text {sat }}$ and $Y$ drives the evaporation. Therefore,

$$
\dot{m}_{\text {evap }}=\dot{v}(\delta) \beta_{f p} A_{p}\left(Y_{s a t}\left(Y_{f, i n}, \theta_{f, \text { in }}\right)-Y_{f, \text { in }}\right) \rho_{f, d r y}
$$

with the mass transfer coefficient $\beta_{f p}$, calculated by the correlation according to Gnielinski [25], and the density of the dry fraction of the fluidization medium $\rho_{f, d r y}$ yielded. The saturation moisture $Y_{s a t}$ is defined as the maximum amount of vapor the fluidization medium can carry. It is determined by utilizing the temperature $\theta_{f, i n}$ and moisture $Y_{f, i n}$.

The balance equations of particle and fluid temperature $\theta_{p}(t)$ and $\theta_{f}(t)$ are derived from the total enthalpy of particles $H_{p}=m_{p, d r y}\left(c_{p, p}+c_{p, l} X\right) \theta_{p}$ and fluidization medium $H_{f}=$ $m_{f, d r y}\left(\left(c_{p, f}+c_{p, v} Y\right) \theta_{f}+Y \Delta h_{\text {evap }}\right)$. The expressions of the enthalpies are derived with respect to time and, afterwards, reformulated such that:

$$
\dot{\theta}_{p}(t)=\frac{\dot{H}_{p}-\left(c_{p, p}+c_{p, l} X\right) \theta_{p} \dot{m}_{p, d r y}-m_{p, d r y} c_{p, l} \theta_{p} \dot{X}}{m_{p, d r y}\left(c_{p, p}+c_{p, l} X\right)}
$$

and

$$
\dot{\theta}_{f}(t)=\frac{\dot{H}_{f}-\left(\left(c_{p, f}+c_{p, v} Y\right) \theta_{f}+Y \Delta h_{\text {evap }}\right) \dot{m}_{f, d r y}-m_{f, d r y}\left(c_{p, v} \theta_{f}+\Delta h_{\text {evap }}\right) \dot{Y}}{m_{f, d r y}\left(c_{p, f}+c_{p, v} Y\right)}
$$

are yielded. By balancing the enthalpy flows, the time derivatives of particle enthalpy $\dot{H}_{p}$ and fluid enthalpy $\dot{H}_{f}$ are determined:

$$
\begin{aligned}
& \dot{H}_{p}(t)=\dot{H}_{\text {inj }}+\dot{H}_{\text {recycle }}-\dot{H}_{\text {out }}+\dot{Q}_{f p}-\dot{H}_{\text {evap }}, \\
& \dot{H}_{f}(t)=\dot{H}_{f, \text { in }}-\dot{H}_{f, \text { out }}-\dot{Q}_{f p}+\dot{H}_{\text {evap }} .
\end{aligned}
$$

It becomes evident that particle phase and fluidization medium are coupled by heat transfer:

$$
\dot{Q}_{f p}(t)=\alpha_{f p} A_{p}\left(\theta_{p}-\theta_{f}\right)
$$

depending on the heat transfer coefficient $\alpha_{f p}$ presented in Gnielinski [25] and enthalpy transfer caused by the evaporated solvent $\dot{H}_{\text {evap }}$. The latter correlates to the evaporation rate $\dot{m}_{\text {evap }}$ introduced in Equation (19) such that:

$$
\dot{H}_{\text {evap }}(t)=\dot{m}_{\text {evap }}\left(c_{p, v} \theta_{f}+\Delta h_{\text {evap }}\right) .
$$

with specific evaporation enthalpy $\Delta h_{\text {evap }}$ at $\theta=0{ }^{\circ} \mathrm{C}$ yielded. The remaining time derivatives of the enthalpies $\dot{H}_{i}$ result from the mass transfer of the injection:

$$
\dot{H}_{i n j}(t)=\dot{m}_{i n j}\left(x_{i n j} c_{p, p}+\left(1-x_{i n j}\right) c_{p, l}\right) \theta_{i n j},
$$

the particle transfers of recycle and withdrawal:

$$
\begin{aligned}
\dot{H}_{\text {recycle }}(t) & =\dot{m}_{p, \text { recycle }, \text { dry }}\left(c_{p, p}+c_{p, l} X_{\text {recycle }}\right) \theta_{\text {recycle }} \\
\dot{H}_{\text {out }}(t) & =\dot{m}_{p, \text { out }, \text { dry }}\left(c_{p, p}+c_{p, l} X\right) \theta_{p}
\end{aligned}
$$


and the enthalpy transfer induced by the fluidization:

$$
\begin{aligned}
\dot{H}_{f, \text { in }} & =\dot{m}_{f, \text { dry,in }}\left(\left(c_{p, g}+c_{p, v} Y_{f, \text { in }}\right) \theta_{f, \text { in }}+Y_{f, \text { in }} \Delta h_{\text {evap }}\right) \text { and } \\
\dot{H}_{f, \text { out }} & =\dot{m}_{f, \text { dry,out }}\left(\left(c_{p, g}+c_{p, v} Y\right) \theta_{f}+Y \Delta h_{\text {evap }}\right) .
\end{aligned}
$$

In the remainder, the focus is on granulation of sodium benzoate, whereby water is used as the solvent. The specific heat capacities of liquid water $c_{p, l}$, water vapor $c_{p, v}$, dry air $c_{p, g}$, as well as the evaporation enthalpy $\Delta h_{\text {evap }}$ depend on the respective temperature. For the calculation, the correlations presented in Glück [26] are utilized. On the contrary, the specific heat capacity of sodium benzoate $c_{p, p}$ depends hardly on temperature under the investigated conditions (Kong et al. [27]). Therefore, the parameter value given in Appendix $\mathrm{A}$ is used for $c_{p, p}$.

Examining the structure of the derived dynamic model, it becomes clear that the two sub-systems, presented in Sections 2.1 and 2.2, are interconnected. For instance, as depicted in Figure 5, the particle size distribution $n(t, L)$ determines the total surface of the particle bed $A_{p}$. According to (19) and (24), the evaporation rate $\dot{m}_{\text {evap }}$ and the heat transfer $\dot{Q}_{f p}$ are correlated to $A_{p}$. Heat transfer has an impact on the enthalpy flows (22) and (23) and therefore on temperatures $\theta_{p}$ and $\theta_{f}$ by Equations (20) and (21). In addition, the moisture contents $X$ and $Y$ depend on the evaporation rate by Equations (13), (16), and (17). Thus, the population balance model affects the thermal conditions. Otherwise, the drying potential $\eta$ depends on $Y$. As Equation (3) states, $\eta$ affects the shell porosity $\epsilon_{\text {shell }}$ and thus the particle growth $G$ presented in (2). In conclusion, the thermal conditions have an impact on $n(t, L)$; thus, a bidirectional coupling between particulate and gas phase is present.

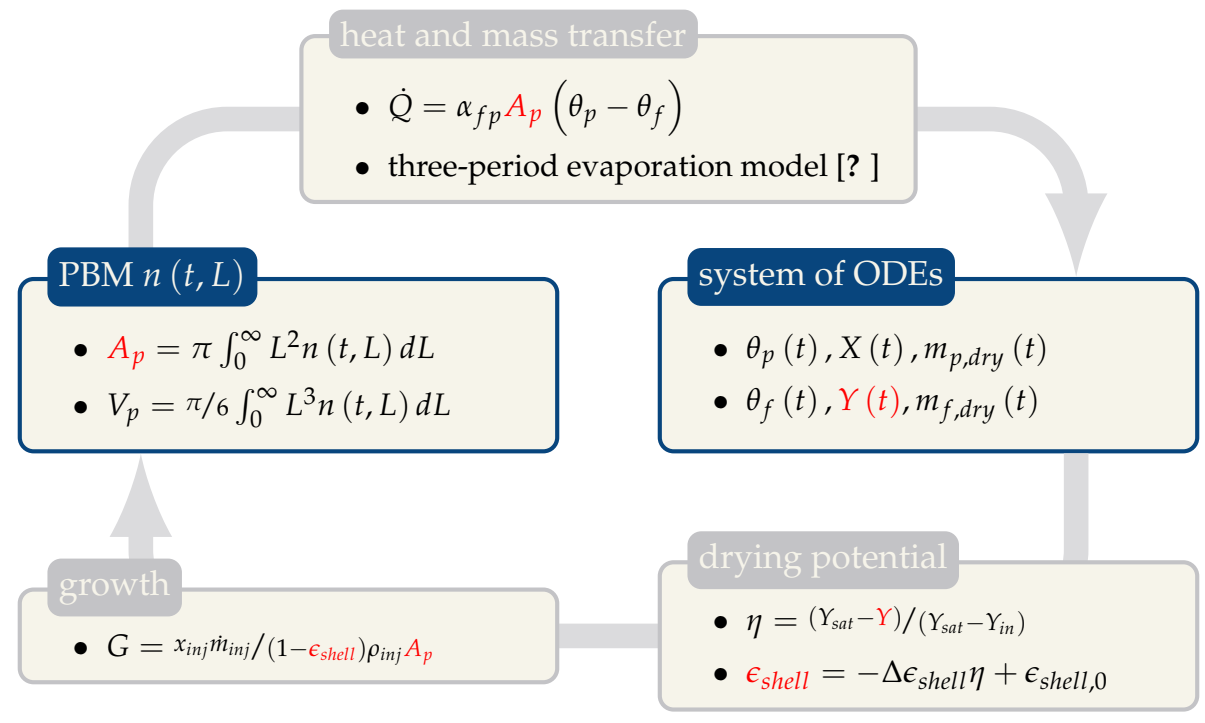

Figure 5. Bidirectional coupling of particulate phase and thermal conditions represented by PBM $n(t, L)$ and the system of ODEs, respectively.

\section{Results and Discussion}

The influence of operating parameters on product properties was investigated by means of simulations. For this purpose, the model presented in Section 2 was implemented in MATLAB (2018a, MathWorks, Natick, MA, USA, 2018) applying a method of lines approach. The partial differential Equation (1) was discretized using a finite volume method, in particular a first order upwind scheme with 200 equidistant grid points was used. The resulting system of ordinary differential equations was solved with the MATLAB built-in solver ode15s. 
To validate the dynamic model, simulation results were compared to the outcome of the theoretical studies of Radichkov et al. [16] and Dreyschultze et al. [18], as well as to the experimental findings of Schmidt et al. [7], Rieck et al. [9], and Hoffmann et al. [10]. Table 1 presents the simulation scenarios. While the first simulation scenario, inspired by $[7,16,18]$, put the focus on the dynamic behavior with respect to the size of milled particles, the second and third scenario investigated the influence of thermal conditions on particle porosity $\epsilon_{p}$. Rieck et al. [9] proved by means of batch experiments, illustrated in Figure 6 and Table 2, a correlation of $\epsilon_{p}$ with operation parameters: an increase of the injection rate $\dot{m}_{i n j}$ and / or a reduction of the temperature of the fluidization medium $\theta_{f, i n}$ leads to a more porous particle surface. In the experiments, Rieck et al. [9] coated glass particles with sodium benzoate. However, similar behavior was observed by Hoffmann et al. [10] for continuous granulation of pure sodium benzoate particles. During long-term FBLG, the inlet moisture content of the fluidization medium $Y_{f, \text { in }}$ may vary over time, thus the fourth simulation scenario presents the response to this typical process disturbance.

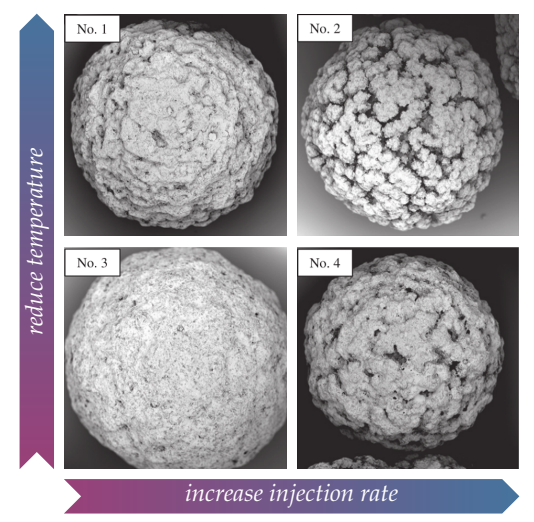

Figure 6. Influence of drying conditions on layer porosity as presented in Rieck et al. [9]: glass particles coated with sodium benzoate according to the operating parameters presented in Table 2.

Table 1. Simulation scenarios according to the simulation results presented in Sections 3.1-3.4.

\begin{tabular}{ccccc}
\hline & $\mu_{\text {mill }}$ & $\dot{m}_{\text {inj }}$ & $\boldsymbol{\theta}_{f, \text { in }}$ & $\Upsilon_{f, \text { in }}$ \\
\hline 1st & $0.70 \mathrm{~mm}$ & - & - & - \\
2nd & - & $50.0 \mathrm{~kg} / \mathrm{h}$ & - & - \\
3rd & - & - & $65.0{ }^{\circ} \mathrm{C}$ & - \\
4th & - & - & - & $15.0 \mathrm{~g}_{\mathrm{f}, \text { wet }} / \mathrm{kg}_{\mathrm{f}, \text { dry }}$ \\
\hline
\end{tabular}

Table 2. Operating parameters related to Rieck et al. [9].

\begin{tabular}{ccccc}
\hline No. & $\boldsymbol{\theta}_{\boldsymbol{f}, \boldsymbol{i n}}$ & $\dot{\boldsymbol{m}}_{\boldsymbol{i n j}}$ & $\boldsymbol{\eta}$ & $\boldsymbol{\epsilon}_{\boldsymbol{s} \boldsymbol{h}}$ \\
\hline 1 & $50^{\circ} \mathrm{C}$ & $0.504 \mathrm{~kg} / \mathrm{h}$ & 0.79 & 0.50 \\
2 & $50{ }^{\circ} \mathrm{C}$ & $0.967 \mathrm{~kg} / \mathrm{h}$ & 0.56 & 0.64 \\
3 & $95^{\circ} \mathrm{C}$ & $0.512 \mathrm{~kg} / \mathrm{h}$ & 0.89 & 0.46 \\
4 & $95^{\circ} \mathrm{C}$ & $1.277 \mathrm{~kg} / \mathrm{h}$ & 0.72 & 0.50 \\
\hline
\end{tabular}

For all simulations, the steady state of the dynamic system with the default parameter set $\Pi_{0}$, presented in Appendix A, is used as the initial state. At simulation time $t=2 \mathrm{~h}$, a single parameter is manipulated according to the scenarios given in Table 1 . After $15 \mathrm{~h}$ of simulation time, the parameter is reset to the default value. 


\subsection{Variations of the Size of Milled Particles}

The experimental study Schmidt et al. [7] proved the significant impact of the milling process on the qualitative behavior of FBLG with an external screen-mill-cycle. While coarse milling leads to the formation of a stable steady state, characterized by a constant particle size distribution $n(t, L)$, fine milling induces self-sustained oscillations of $n(t, L)$. Those oscillations lead to variations of the particle size distribution and mass flows. In the worst case, they may cause a breakdown of the process. Therefore, they are highly undesired. To predict and avoid instabilities in FBLG processes, the dynamic model, presented in Section 2, has to be capable of reproducing these different forms of dynamic behavior. To prove this, the first simulation scenario is utilized.

As depicted in Figure 7a, the reduction of the diameter of milled particles from $\mu_{\text {mill }}=0.8 \mathrm{~mm}$ to $0.7 \mathrm{~mm}$ at $t_{1}=2 \mathrm{~h}$ induces self-sustained oscillations of the normalized particle size distribution $q(t, L)$. As a consequence, the Sauter diameter $d_{32}$, defined as:

$$
d_{32}=6 V_{p} / A_{p}=\frac{\int_{0}^{\infty}\left(L^{3} n(t, L)\right) d L}{\int_{0}^{\infty}\left(L^{2} n(t, L)\right) d L}
$$

and presented in Figure 8, varies with time, as well. By means of Equation (6), a constant bed mass is ensured. If, in accordance with the simulation results shown in Figure 8, the variation of particle porosity $\epsilon_{p}$ is neglected, the overall bed volume $V_{p}$ can be considered as constant. Therefore, the oscillations of $d_{32}$ are motivated by the variations of the total bed surface $A_{p}$.
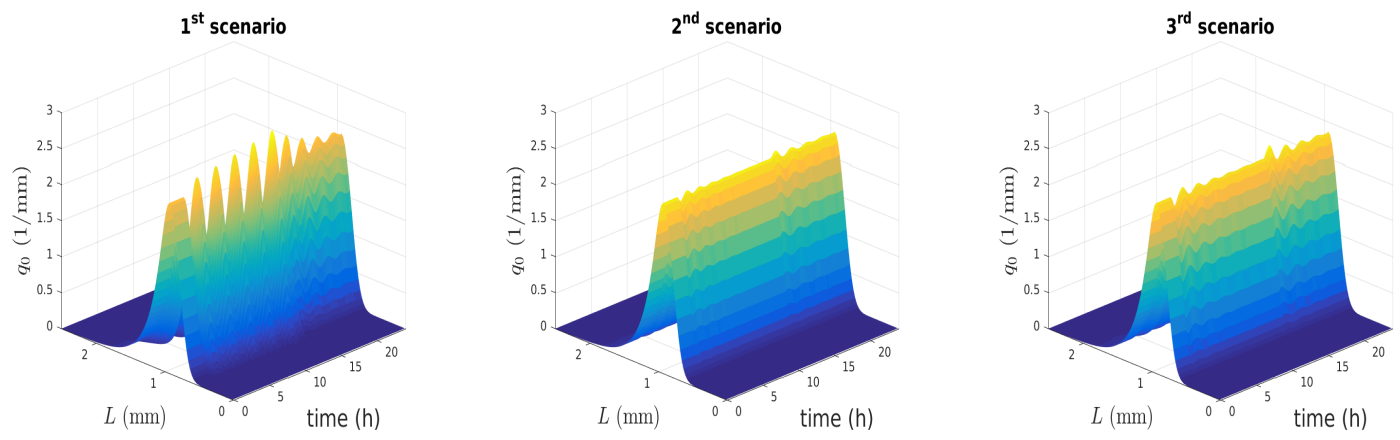

Figure 7. Normalized particle size distribution $q_{0}(t, L)$ related to the first, second, and third simulation scenario.
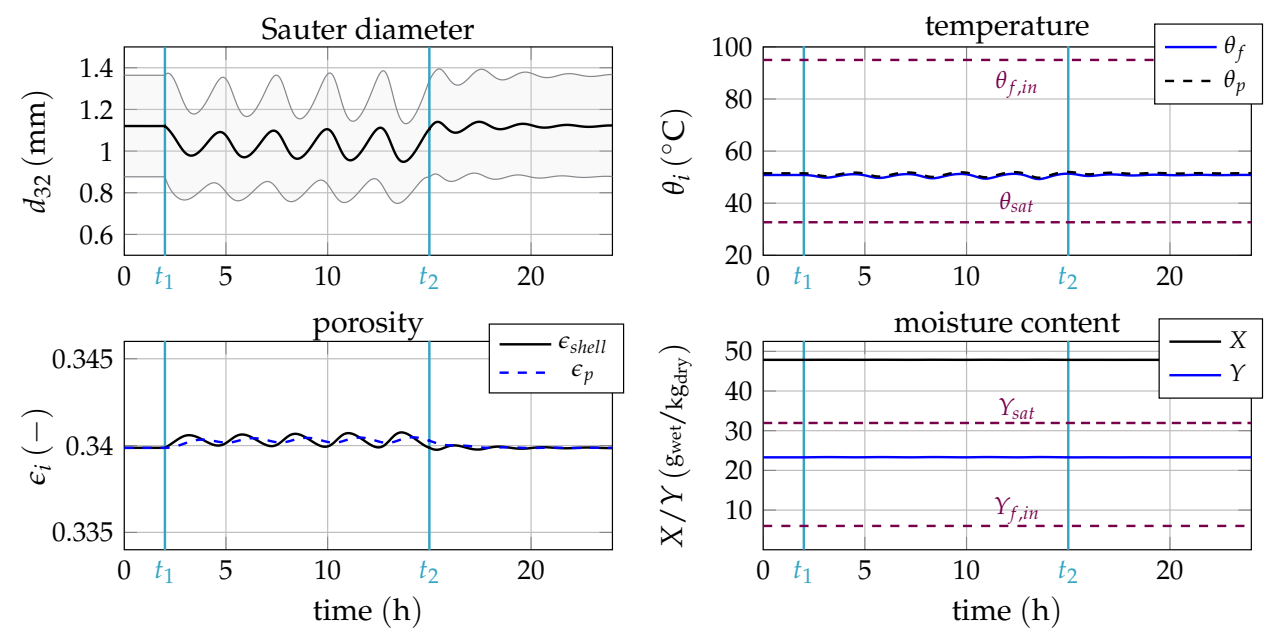

Figure 8. Simulation results of the first scenario: the setpoint switch of mean size of milled particles $\mu_{\text {mill }}$ from $0.8 \mathrm{~mm}$ to $0.7 \mathrm{~mm}$ at $t_{1}=2 \mathrm{~h}$ leads to the arising of self-sustained oscillations. After the reset of $\mu_{\text {mill }}$ at $t_{2}$, the oscillations decay and the dynamic system reaches steady state again. 
Alterations of $A_{p}$ change the heat transfer between fluidization medium and particles, $\dot{Q}_{f p}$. Thus, the temperatures of particles $\theta_{p}$ and fluidization medium $\theta_{f}$ vary, leading to a change of the drying process. As a consequence, the moisture contents $X$ and $Y$ change, inducing a variation of the drying potential $\eta$. As $\epsilon_{\text {shell }}$ depends on $\eta$, the porosity of the shell changes, as well. This leads throughout simulation time to a change of the apparent particle porosity $\epsilon_{p}$ and, as a consequence, to a variation of the particles density $\rho_{p}$.

At $t_{2}=15 \mathrm{~h}$, the parameter $\mu_{\text {mill }}$ is reset to $0.8 \mathrm{~mm}$. As a consequence, the oscillations decay such that the system settles, after sufficient long simulation time, at steady state again. Thereby, the steady state and the initial state share the same values.

\subsection{Variations of Injection Rate}

As depicted in Figure 6, an increased injection rate $\dot{m}_{i n j}$ leads to a more porous particle, surface, resulting in a higher shell porosity $\epsilon_{\text {shell }}$. To reproduce this experimental observation by simulations, the second scenario was introduced: the injection rate $\dot{m}_{i n j}$ was increased from $40 \mathrm{~kg} / \mathrm{h}$ to $50 \mathrm{~kg} / \mathrm{h}$ at $t_{1}=2 \mathrm{~h}$ and, at $t_{2}=15 \mathrm{~h}$, reset to the default value.

The increase of the injection rate $\dot{m}_{i n j}$ at $t_{1}$ raised the amount of supplied salt and solvent. While the first had an impact on the particle growth and thus on normalized particle size distribution $q(t, L)$, as well as Sauter diameter $d_{32}$, hardly observed in simulation results shown in Figures $7 \mathrm{~b}$ and 9 , the second lead to significant variations of the thermal conditions. Since more solvent was injected, the particles moisture $X$ increased from $47.8 \mathrm{~g}_{\text {wet }} / \mathrm{kg}_{\text {dry }}$ to $49.1 \mathrm{~g}_{\text {wet }} / \mathrm{kg}_{\text {dry }}$. Considering Equation (18), this led, as long as the second period drying proceeds, to an enhanced evaporation rate $\dot{m}_{\text {evap }}$. As a consequence, the moisture of the fluidization medium $Y$ was raised from $23.3 \mathrm{~g}_{\text {wet }} / \mathrm{kg}_{\text {dry }}$ to $27.6 \mathrm{~g}_{\text {wet }} / \mathrm{kg}_{\text {dry }}$. The resulting drop of the drying potential $\eta$ led, in accordance with Equation (3), to a higher shell porosity $\epsilon_{\text {shell }}$. As can be seen in Figure 9, the thermal conditions discussed so far are characterized by a fast transition from the initial to the new steady state. The transition of the apparent particle porosity $\epsilon_{p}$ to the new steady state is much slower. This can be explained by the nature of $\epsilon_{p}$ : the apparent particle porosity is an integral value. Therefore, all particles with an apparent porosity $\epsilon_{p}$ differing from current shell porosity $\epsilon_{\text {shell }}$ have to be removed from the process. After that, the apparent particle porosity $\epsilon_{p}$ and the porosity of the shell $\epsilon_{\text {shell }}$ share the same value.
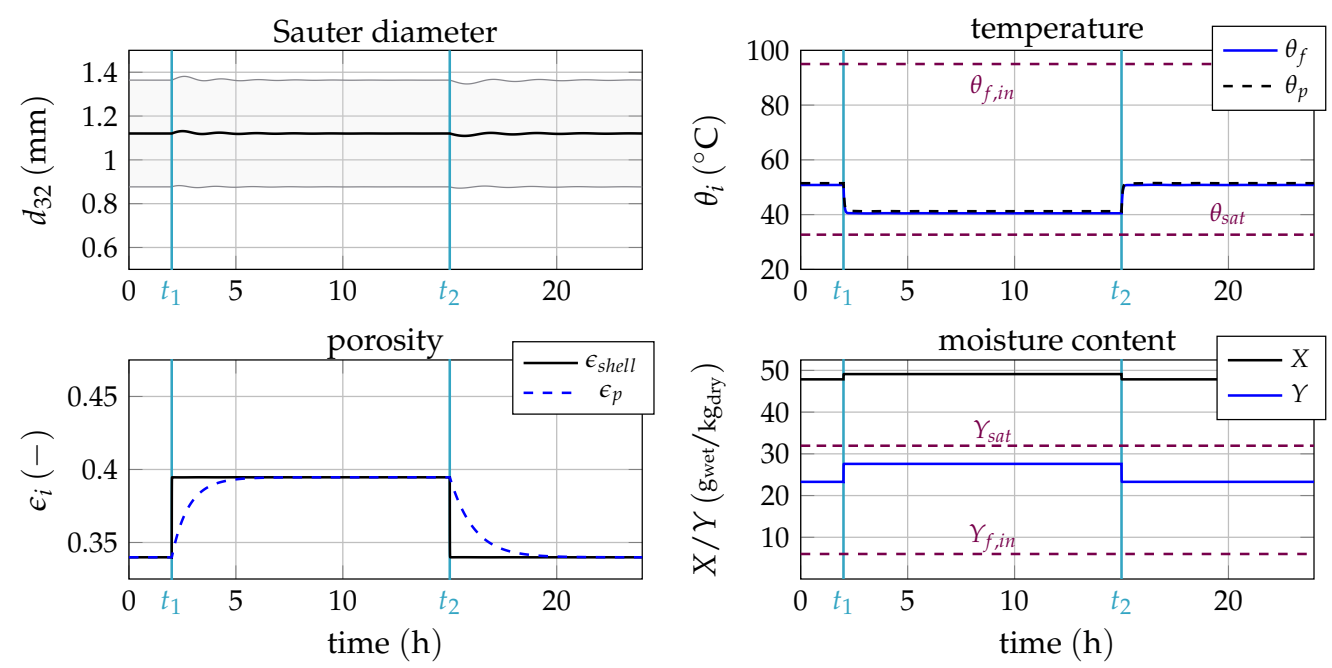

Figure 9. Simulation results of the second scenario: an increase of injection rate $\dot{m}_{i n j}$ from $40 \mathrm{~kg} / \mathrm{h}$ to $50 \mathrm{~kg} / \mathrm{h}$ at $t_{1}$ induces variations of thermal conditions, resulting in an increased particle porosity $\epsilon_{p}$. After resetting $\dot{m}_{i n j}$ to the default value, the dynamic states and particle properties settle at the (initial) steady state again. Regard the different time scales of the step response at $t_{1}$ and $t_{2}$ illustrated in Figure 10 . 
At $t_{2}$, the injection rate $\dot{m}_{i n j}$ was decreased to the default value. Again, normalized particle size distribution $q(t, L)$ and Sauter diameter $d_{32}$ varied only slightly. The thermal states $X, Y, \theta_{p}$, and $\theta_{f}$ reached the new steady state rapidly. Due to the decreasing moisture of the fluidization medium $Y$, the drying potential $\eta$ increased. This led to a reduced shell porosity $\epsilon_{\text {shell }}$ and, as a consequence, to a decreased particle porosity $\epsilon_{p}$. The transition of $\epsilon_{p}$ to the corresponding steady state value, $\epsilon_{s h e l l}$, required a long period of time again. A comparison of the transition of $\epsilon_{p}$ surrounding the steps at $t_{1}$ and $t_{2}$ is presented in Figure 10. Therefore, $\Delta t=t-t_{i}$ and the deviation of particle porosity $\Delta \epsilon_{p}=\left|\epsilon_{p}(t)-\epsilon_{p}\left(t_{i}\right)\right|$ were introduced for $i=\{1,2\}$. It became evident that the time constant $\tau_{1}$, belonging to the step at $t_{1}$, was smaller than time constant $\tau_{2}$.

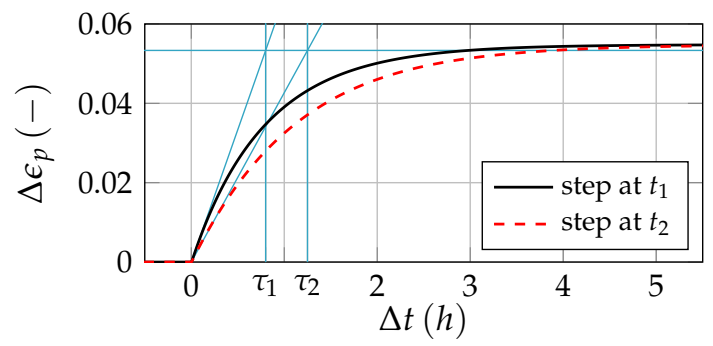

Figure 10. Normalized particle porosity $\Delta \epsilon_{p}$ surrounding the set point switches of $\dot{m}_{i n j}$ at $t_{1}$ and $t_{2}$ according to the second simulation scenario.

The simulation results of the second scenario are in qualitative agreement with the experimental observations of Rieck et al. [9] presented in Figure 6. The increased injection rate $\dot{m}_{i n j}$ led to a higher shell porosity $\epsilon_{\text {shell }}$ and an increased particle porosity $\epsilon_{p}$.

\subsection{Variations of the Temperature of the Fluidization Medium}

In further experiments, depicted in Figure 6 and Table 2, Rieck et al. [9] showed that the temperature of the fluidization medium $\theta_{f, \text { in }}$ influences the shell porosity $\epsilon_{\text {shell }}$ : a lowering of $\theta_{f, \text { in }}$ increased $\epsilon_{\text {shell }}$. To address these experiments, the third simulation scenario was introduced. There, the temperature $\theta_{f, i n}$ was decreased from $95^{\circ} \mathrm{C}$ to $70^{\circ} \mathrm{C}$ at $t_{1}$ and, at $t_{2}$, reset to the default value of $95^{\circ} \mathrm{C}$.

As presented in Figures $7 \mathrm{c}$ and 11, the manipulation of $\theta_{f, i n}$ at $t_{1}$ has a slight influence on the normalized particle size distribution $q(t, L)$ and Sauter diameter $d_{32}$. Otherwise, the reduction of $\theta_{f, \text { in }}$ led to a shift of the saturation point. As a consequence, the saturation moisture $Y_{\text {sat }}$ descended from $32.0 \mathrm{~g}_{\text {wet }} / \mathrm{kg}_{\text {dry }}$ to $23.3 \mathrm{~g}_{\text {wet }} / \mathrm{kg}_{\text {dry }}$. A reduced saturation moisture $Y_{\text {sat }}$ resulted, according to Equation (19), in a decreased evaporation rate $\dot{m}_{\text {evap }}$. Following Equation (3), a reduction of the saturation moisture $Y_{\text {sat }}$ increased the drying potential $\eta$. Since $\epsilon_{\text {shell }}$ is negatively correlated with $\eta$, the porosity of the shell increased. This lead, over simulation time, to an increasing particle porosity $\epsilon_{p}$. At $t_{2}$, the temperature of the fluidization medium was reset. As in the previous simulation scenario, the system settled at the steady state corresponding to the default parameter set.

Again, the simulation results and experimental findings of Rieck et al. [9] are in qualitative agreement: A reduction of $\theta_{f, \text { in }}$ leads to an increased shell and particle porosity.

\subsection{Disturbance of the Inlet Moisture Content of the Fluidization Medium}

In general, continuously-operated FBLG is a slow process. Therefore, the environmental conditions may alter over time. For instance, the temperature and moisture content of the fed fluidization medium, e.g., air, may change. While the temperature $\theta_{f, i n}$ can be changed by heating the fluid to the desired value, the moisture of the fluidization medium $Y_{f, \text { in }}$ can only be manipulated with much effort. By accepting variations of $Y_{f, \text { in }}$ as process disturbances, one often forgoes controlling $Y_{f, i n}$. To study the influence of the described disturbance on the dynamic behavior, as well as the product 
properties, the four scenario was introduced: $Y_{f, \text { in }}$ was increased from default value $6.0 \mathrm{~g}_{\text {wet }} / \mathrm{kg}_{\mathrm{dry}}$ to $15.0 \mathrm{~g}_{\mathrm{wet}} / \mathrm{kg}_{\text {dry }}$ at $t_{1}$ and reset at $t_{2}$.
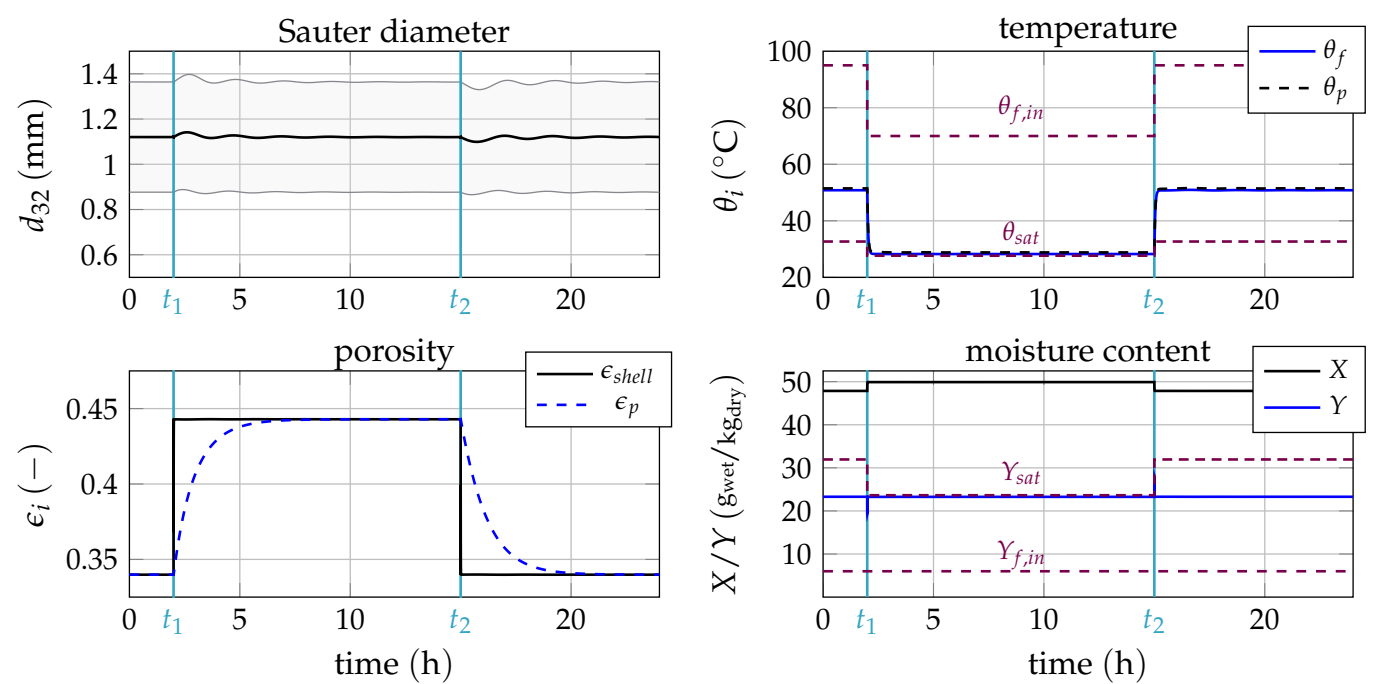

Figure 11. Simulation results of the third scenario: the reduction of the temperature of the fluidization medium $\theta_{f, \text { in }}$ from $95^{\circ} \mathrm{C}$ to $70{ }^{\circ} \mathrm{C}$ at $t_{1}$ shifts the saturation point. This induces variations of thermal conditions and thus to a change of shell $\epsilon_{\text {shell }}$ and particle porosity $\epsilon_{p}$. After resetting $\theta_{f, \text { in }}$ to the default value at $t_{2}$, the dynamic states and particle properties settle at the (initial) steady state again.

Referring to Figure 12, the disturbance has neither a significant influence on the qualitative behavior, nor on particle properties. While the raised $Y_{f, \text { in }}$ at $t_{1}$ increased the moisture content $Y$ from $23.3 \mathrm{~g}$ wet $/ \mathrm{kg}_{\text {dry }}$ to $32.2 \mathrm{~g}_{\mathrm{wet}} / \mathrm{kg}_{\text {dry }}$, it also shifted the saturation point. As a result, $Y_{\text {sat }}$ was raised from $32.7 \mathrm{~g}_{\mathrm{wet}} / \mathrm{kg}_{\text {dry }}$ to $36.5 \mathrm{~g}$ wet $/ \mathrm{kg}_{\text {dry }}$. Even if the changes of $Y_{f, i n}, Y$, and $Y_{\text {sat }}$ were quite large, the drying potential $\eta$ varied only slightly as $\left(Y_{S a t}-Y_{f, i n}\right)$ remained almost constant. The small shift of $\eta$ was reduced from 0.334 to 0.312 , inducing slight variations of shell porosity $\epsilon_{\text {shell }}$ and particle porosity $\epsilon_{p}$. Therefore, the normalized particle size distribution $q(t, L)$ stayed almost constant, resulting in a uniform Sauter diameter $d_{32}$.
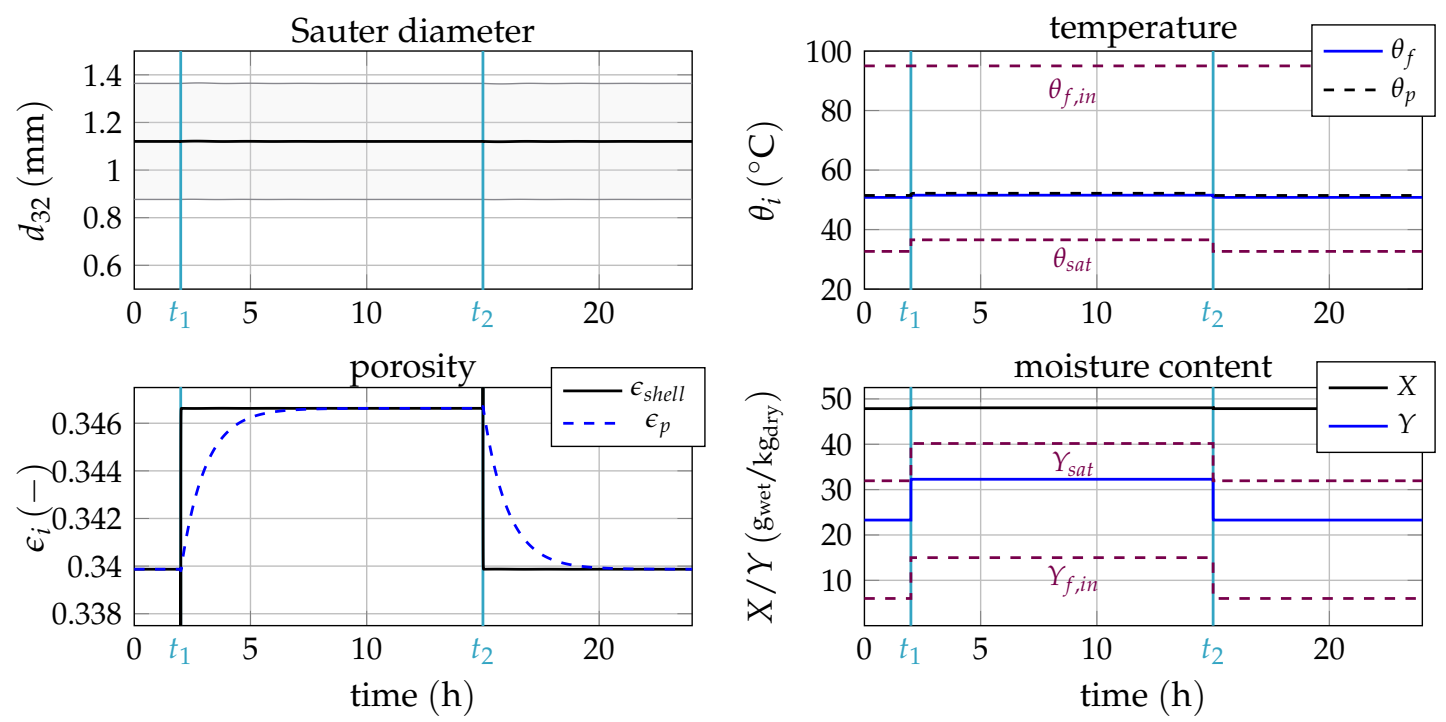

Figure 12. Simulation results of fourth scenario: the disturbance of the moisture content of the fluid at inlet $Y_{\text {in }}$ at $t_{1}$ results in small variations of the thermal conditions and particle properties. 


\section{Conclusions and Outlook}

In this contribution, the influence of operation conditions on the qualitative process behavior of a continuously-operated FBLG with external scree-mill-cycle and key product properties was investigated by means of a simulation study. The dynamic model considers the dynamics of the particle size distribution $n(t, L)$, as well as the thermal states of particles and fluidization medium. The model requires the following parameters:

1. caloric parameters (e.g., evaporation enthalpy $\Delta h_{\text {evap }}$ or heat capacities $c_{p, i}$ ),

2. heat and mass transfer coefficients $\left(\alpha_{g p}\right.$ and $\left.\beta_{g p}\right)$,

3. parameters related to the drying curve $\left(p, x_{c r i t}\right.$, and $\left.x_{e q}\right)$,

4. parameters of the relation between shell porosity and drying potential $\left(\Delta \epsilon_{\text {shell }}\right.$ and $\left.\epsilon_{\text {shell }, 0}\right)$, and

5. parameters of the periphery (mill and screen).

The parameters have been taken from material databases (1), have been approximated with well-established correlations (2), or have been fitted to data of independent experiments $(3,4)$. For the screening and milling process (5). idealized models were utilized.

In the first simulation scenario, it was shown that the designed model was capable of reproducing the experimental observations of Schmidt et al. [7], as well as the theoretical findings of Dreyschultze et al. [18] and Radichkov et al. [16]. In particular, it was shown that the milling process has a major influence on the dynamics of the FBLG: while coarse milling, characterized by a large mean diameter of milled particles $\mu_{\text {mill }}$, leads to the formation of a steady state, fine milling induces self-sustained oscillations. On the other hand, variations of the thermal conditions lead, in accordance with Figure 6 and Table 2 in presented experimental results of Rieck et al. [9], to a significant change of product properties. As shown by the second and third simulation scenarios, variations of the temperature $\theta_{f, i n}$ and injection rate $\dot{m}_{i n j}$ induce a change of the drying potential $\eta$ and thus of $\epsilon_{p}$. Finally, the fourth simulation scenario indicated a high robustness of system dynamics and particle properties against variations of the inlet moisture content of the fluidization medium $Y_{f, i n}$.

The simulation results confirmed the bidirectional coupling of population balance model and the system of ODEs derived in Section 2 and presented in Figure 5: A manipulation of $n(t, L)$ induces variations of the thermal states, as well as product properties and vice versa. Even though the interaction seams reasonable, the mutual influence is quite small. However, an important feature is still missing: Antonyuk et al. [3] pointed out that the breakage of particles depends on particle porosity $\epsilon_{p}$. So far, the model of the milling process (12) does not consider this dependency. Since $\epsilon_{p}$ depends on $\eta$ and therefore on $Y, Y_{\text {sat }}$, and $Y_{i n}$, this extension will increase the influence of the thermal conditions on $n(t, L)$ and thus on the dynamic behavior. This extension was beyond the scope of the present paper. It is required to reproduce the experimental findings by Schmidt et al. [8]. There, the thermal conditions, represented by the drying potential $\eta$, have a significant influence on the qualitative behavior of the FBLG.

The derived dynamic model can be used to design granulation processes with tailor-made product properties including the size, porosity, temperature, and moisture of the formulated particles. These quantities are important for further processing and final product formulation. Based on the established model, various controllers can be designed and validated. Palis and Kienle [28,29] and Cotabarren et al. [30] proved that feedback controllers are suitable to ensure the operation of FBLG processes under stable steady state conditions. Bück et al. [31] presented a strategy to control the moisture content of particulate solid as a product property in a drying process. As FBLG aims at a stable operation and the formation of particles with tailored properties, multi-variable control strategies are promising to fulfil both requirements.

Author Contributions: The concept and methodologies were developed by C.N., A.B., A.K., L.M., and E.T. Investigations were made by C.N. and A.B. C.N. did the software implementation and wrote the draft. The draft was reviewed and edited by A.B., A.K., S.P., L.M., and E.T. S.P. and A.K. were responsible for the funding acquisition.

Funding: The financial support of DFG (Deutsche Forschungsgemeinschaft) within the priority program SPP1679 is gratefully acknowledged.

Conflicts of Interest: The authors declare no conflict of interest. 


\section{Nomenclature}

A surface area $\left(\mathrm{m}^{2}\right)$

$c_{p} \quad$ specific heat capacity $(\mathrm{J} / \mathrm{kg} \cdot \mathrm{K})$

$d_{32} \quad$ Sauter diameter (m)

$G$ particle growth $(\mathrm{m} / \mathrm{s})$

$h \quad$ mass specific enthalpy $(\mathrm{J} / \mathrm{kg})$

$H$ total enthalpy $(\mathrm{J})$

$\dot{H} \quad$ enthalpy flow $(\mathrm{J} / \mathrm{s})$

K drain (1/s)

$L \quad$ particle size $(\mathrm{m})$

$m$ mass $(\mathrm{kg})$

$\dot{m}$ mass flow $(\mathrm{kg} / \mathrm{s})$

$n$ number-based particle size distribution $(1 / \mathrm{m})$

$\dot{n} \quad$ particle flow $(1 / \mathrm{m} \cdot \mathrm{s})$

$p \quad$ material specific drying characteristics (-)

$q$ normalized particle size distribution $(1 / \mathrm{m})$

$\dot{Q}$ heat flow $(\mathrm{J} / \mathrm{s})$

$t \quad$ simulation time (h)

$T$ separation function (-)

$V \quad$ volume $\left(\mathrm{m}^{3}\right)$

$x \quad$ (mass) fraction of solid (-)

$X \quad$ moisture content of solid ( $\left.\mathrm{g}_{\text {wet }} / \mathrm{kg}_{\text {wet }}\right)$

$Y$ moisture content of fluid ( $\left.\mathrm{g}_{\text {wet }} / \mathrm{kg}_{\text {wet }}\right)$

\section{Greek letters}

$\alpha$ heat transfer coefficient $\left(\mathrm{W} / \mathrm{m}^{2} \cdot \mathrm{K}\right)$

$\beta$ mass transfer coefficient $(\mathrm{m} / \mathrm{s})$

$\delta \quad$ normalized moisture content (-)

$\eta \quad$ drying potential (-)

$\theta$ temperature $\left({ }^{\circ} \mathrm{C}\right)$

$\mu$ mean diameter $(\mathrm{m})$

$\dot{v}$ normalized drying velocity (-)

$\Pi$ parameter set (-)

$\rho \quad$ mass density $\left(\mathrm{kg} / \mathrm{m}^{3}\right)$

$\sigma \quad$ variance $(\mathrm{m})$

$\tau \quad$ time constant (h)

Subscripts

dry dry part of particles or fluidization medium

evap evaporation

$f \quad$ fluidization medium

fp fluid phase to particle phase

fine particle fine fraction

in inlet

inj injection

$l \quad$ liquid

mill milled particles

out particle withdrawal or fluid exhaust

oversized particle oversized fraction

$p \quad$ particle phase

prod particle product fraction

recycle particle recycle

$s \quad$ suspension

sat saturation point

screen screen

solvent solvent on particles or in fluidization medium

shell (particle) shell

$v \quad$ vapor 


\section{Appendix A. Default Parameter Set}

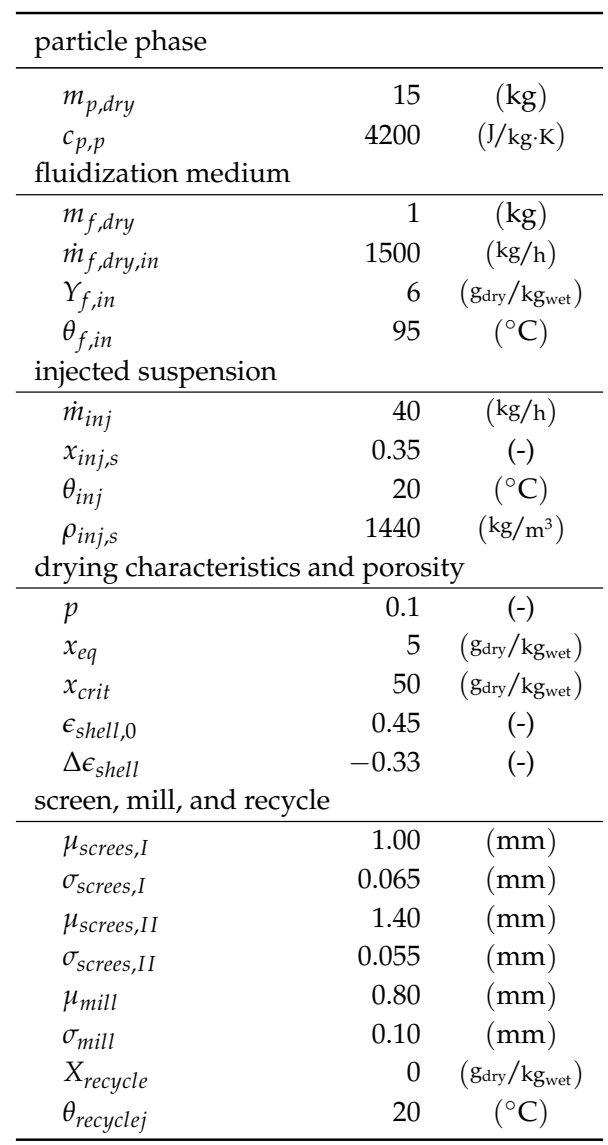

\section{References}

1. Mörl, L.; Heinrich, S.; Peglow, M. Fluidized bed spray granulation. In Granulation; Salman, A.D., Hounslow, M.J., Seville, J.P.K., Eds.; Handbook of Powder Technology; Elsevier Science B.V.: Amsterdam, The Netherlands, 2007; Volume 11, pp. 21-188.

2. Tsotsas, E. Influence of Drying Kinetics on Particle Formation: A Personal Perspective. Dry. Technol. 2012, 30, 1167-1175. [CrossRef]

3. Antonyuk, S.; Tomas, J.; Heinrich, S.; Mörl, L. Breakage behavior of spherical granulates by compression. Chem. Eng. Sci. 2005, 60, 4031-4044. [CrossRef]

4. Grünewald, G.; Westhoff, B.; Kind, M. Fluidized Bed Spray Granulation: Nucleation Studies with Steady-State Experiments. Dry. Technol. 2010, 28, 349-360. [CrossRef]

5. Cotabarren, I.; Schulz, P.G.; Bucalá, V.; Piña, J. Modeling of an industrial double-roll crusher of a urea granulation circuit. Powder Technol. 2008, 183, 224-230. [CrossRef]

6. Schmidt, M.; Bück, A.; Tsotsas, E. Experimental investigation of process stability of continuous spray fluidized bed layering with internal separation. Chem. Eng. Sci. 2015, 126, 55-66. [CrossRef]

7. Schmidt, M.; Rieck, C.; Bück, A.; Tsotsas, E. Experimental investigation of process stability of continuous spray fluidized bed layering with external product separation. Chem. Eng. Sci. 2015, 137, 466-475. [CrossRef]

8. Schmidt, M.; Bück, A.; Tsotsas, E. Experimental investigation of the influence of drying conditions on process stability of continuous spray fluidized bed layering granulation with external product separation. Powder Technol. 2017, 320, 474-482. [CrossRef]

9. Rieck, C.; Hoffmann, T.; Bück, A.; Peglow, M.; Tsotsas, E. Influence of drying conditions on layer porosity in fluidized bed spray granulation. Powder Technol. 2015, 272, 120-131. [CrossRef]

10. Hoffmann, T.; Rieck, C.; Schmidt, M.; Bück, A.; Peglow, M.; Tsotsas, E. Prediction of Shell Porosities in Continuous Fluidized Bed Spray Layering. Dry. Technol. 2015, 33, 1662-1670. [CrossRef] 
11. Sondej, F.; Peglow, M.; Bück, A.; Tsotsas, E. Experimental investigation of the morphology of salt deposits from drying sessile droplets by white-light interferometry. AIChE J. 2018, 64, 2002-2016. [CrossRef]

12. Diez, E.; Meyer, K.; Bück, A.; Tsotsas, E.; Heinrich, S. Influence of process conditions on the product properties in a continuous fluidized bed spray granulation process. Chem. Eng. Res. Des. 2018, 139, 104-115. [CrossRef]

13. Ramkrishna, D. Population Balances: Theory and Applications to Particulate Systems in Engineering; Academic Press: San Diego, CA, USA, 2000.

14. Vreman, A.; van Lare, C.; Hounslow, M. A basic population balance model for fluid bed spray granulation. Chem. Eng. Sci. 2009, 64, 4389-4398. [CrossRef]

15. Heinrich, S.; Peglow, M.; Ihlow, M.; Henneberg, M.; Mörl, L. Analysis of the start-up process in continuous fluidized bed spray granulation by population balance modelling. Chem. Eng. Sci. 2002, 57, 4369-4390. [CrossRef]

16. Radichkov, R.; Müller, T.; Kienle, A.; Heinrich, S.; Peglow, M.; Mörl, L. A numerical bifurcation analysis of continuous fluidized bed spray granulation with external product classification. Chem. Eng. Process. 2006, 45, 826-837. [CrossRef]

17. Hampel, N.; Bück, A.; Peglow, M.; Tsotsas, E. Continuous pellet coating in a Wurster fluidized bed process. Chem. Eng. Sci. 2013, 86, 87-98. [CrossRef]

18. Dreyschultze, C.; Neugebauer, C.; Palis, S.; Bück, A.; Tsotsas, E.; Heinrich, S.; Kienle, A. Influence of zone formation on stability of continuous fluidized bed layering granulation with external product classification. Particuology 2015, 23, 1-7. [CrossRef]

19. Neugebauer, C.; Palis, S.; Bück, A.; Tsotsas, E.; Heinrich, S.; Kienle, A. A dynamic two-zone model of continuous fluidized bed layering granulation with internal product classification. Particuology 2017, 31, 8-14. [CrossRef]

20. Bück, A.; Neugebauer, C.; Meyer, K.; Palis, S.; Diez, E.; Kienle, A.; Heinrich, S.; Tsotsas, E. Influence of operation parameters on process stability in continuous fluidised bed layering with external product classification. Powder Technol. 2016, 300, 37-45. [CrossRef]

21. Drechsler, J.; Peglow, M.; Heinrich, S.; Ihlow, M.; Mörl, L. Investigating the dynamic behavior of fluidized bed spray granulation processes applying numerical simulation tools. Chem. Eng. Sci. 2005, 60, 3817-3833. [CrossRef]

22. Dosta, M.; Heinrich, S.; Werther, J. Fluidized bed spray granulation: Analysis of the system behavior by means of dynamic flowsheet simulation. Powder Technol. 2010, 204, 71-82. [CrossRef]

23. Ennis, B.J.; Tardos, G.; Pfeffer, R. A microlevel-based characterization of granulation phenomena. Powder Technol. 1991, 65, 257-272. [CrossRef]

24. van Meel, D. Adiabatic convection batch drying with recirculation of air. Chem. Eng. Sci. 1958, 9, 36-44. [CrossRef]

25. Gnielinski, V. G9-Wärmeübertragung Partikel—Fluid in durchströmten Haufwerken. In VDI Wärmeatlas; VDI Verlag: Düsseldorfer, Germany, 2013.

26. Glück, B. Zustands- und Stoffwerte, 2nd ed.; Verlag für Bauwesen GmbH: Berlin, Germany, 1991.

27. Kong, Y.X.; Di, Y.Y.; Qi, Y.D.; Yang, W.W.; Tan, Z.C. Low temperature heat capacities and standard molar enthalpy of formation of sodium benzoate $\mathrm{C}_{6} \mathrm{H}_{5} \mathrm{COONa}$ (s). Thermochim. Acta 2009, 488, 27-32. [CrossRef]

28. Palis, S.; Kienle, A. Stabilization of continuous fluidized bed spray granulation with external product classification. Chem. Eng. Sci. 2012, 70, 200-209. [CrossRef]

29. Palis, S.; Kienle, A. Discrepancy based control of particulate processes. J. Process Control 2014, $24,33-46$. [CrossRef]

30. Cotabarren, I.M.; Bertín, D.E.; Bucalá, V.; Piña, J. Feedback control strategies for a continuous industrial fluidized-bed granulation process. Powder Technol. 2015, 283, 415-432. [CrossRef]

31. Bück, A.; Seidel, C.; Dürr, R.; Neugebauer, C. Robust feedback control of convective drying of particulate solids. J. Process Control 2018, 69, 86-96. [CrossRef]

(C) 2018 by the authors. Licensee MDPI, Basel, Switzerland. This article is an open access article distributed under the terms and conditions of the Creative Commons Attribution (CC BY) license (http:/ / creativecommons.org/licenses/by/4.0/). 